\title{
Peran gaya pengasuhan dan penanganan secara religius terhadap resiliensi pada remaja dengan HIVIAIDS di DenpasarBali
}

R.A. Dinda Nabilla Fayakun Darmawan ${ }^{1 *}$, Jane Savitri ${ }^{2}$, Jacueline M.Tj. ${ }^{3}$

Program Magister Psikologi Sains, Universitas Kristen Maranatha, Indonesia

\begin{tabular}{l}
\hline Info Artikel \\
\hline Sejarah Artikel: \\
Diterima \\
I0 November 2019 \\
Direview \\
08 Februari 2020 \\
Disetujui \\
28 Februari 2020 \\
Dipublikasikan \\
05 Oktober 2020 \\
\hline Keywords: \\
Adolescence Living \\
with HIVIAIDS, \\
Parenting Style, \\
Religious Coping, \\
Resiliency
\end{tabular}

Abstrak
Objektif: Tujuan dari penelitian ini adalah mengetahui peran parenting style dan religious coping
secara bersama-sama maupun parsial terhadap resiliency pada remaja dengan HIVIAIDS di
Denpasar-Bali. Penelitian ini menggunakan metode kuantitatif dengan 103 subjek remaja
dengan HIVIAIDS di Denpasar-Bali

Metode: Penelitian menggunakan desain kuantitatif dengan 103 responden remaja penderita HIVIAIDS yang tinggal di DenpasarBali. Data penelitian diolah menggunakan multiple regression dan linear regression.

Temuan: Berdasarkan analisis yang dilakukan dalam penelitian ini, diketahui bahwa: parenting style Ayah dan religious coping bersama-sama berperan terhadap resiliency $\left(\rho<.05, R^{2}=0,384\right)$; parenting style lbu dan religious coping bersama-sama memiliki peran terhadap resiliency $(\rho<.05$, $\left.\mathrm{R}^{2}=0,365\right)$.

Kesimpulan: Perhitungan secara parsial diperoleh hasil bahwa parenting style authoritative baik Ayah maupun lbu, parenting style lbu authoritarian, parenting style Ayah dan negative religious coping, parenting style lbu dan positive religious coping, serta parenting style lbu dan negative religious coping yang memiliki peran terhadap resiliency, sedangkan variabel lain tidak berperan terhadap resiliency.

The role of parenting styles and handling religiously on the resilience of
adolescents with HIVIAIDS in Denpasar, Bali

Objectives: The purpose of this research is to find out the role of parenting style and religious coping simultaneously and partially towards resiliency on adolescence living with HIVIAIDS in Denpasar-Bali.

Method: The research uses quantitative method with 103 adolescence living with HIVIAIDS in Denpasar-Bali. The data of this research are processed using multiple regression and linear regression SPSS 24.0.

Findings: Paternal parenting style and religious coping simultaneously are significantly influential towards resiliency $\left(\rho<.05, R^{2}=0,384\right)$; maternal parenting style and religious coping simultaneously are significantly influential towards resiliency $\left(\rho<.05, R^{2}=0,365\right)$.

Conclusions: Partial calculations shows authoritative parenting style both father and mother, authoritarian parenting style mother, paternal parenting style and negative religious coping, maternal parenting style and positive religious coping, also maternal parenting style and positive religious coping which have a role towards resiliency, while other variables do not give any momentous role in resiliency,

\footnotetext{
*Alamat korespondensi:

Universitas Kristen Maranatha

Jl. Surya Sumantri No.65, Sukawarna, Kec. Sukajadi, Kota Bandung, Jawa Barat 40164

nabillasee@yahoo.com
} 


\section{Pendahuluan}

Kasus HIVIAIDS (Human Immuno Deficiency Virus/Acquired Immuno Deficiency Syndrome) di Indonesia setiap tahunnya kian melonjak cepat. Perilaku dan gaya hidup bebas, seperti seks bebas, pemakaian narkoba dengan jarum suntik yang bergantian, dan lain-lainnya menjadi alasan mengapa kasus tersebut meningkat. Menurut laporan Joint United Nations Programme on HIV and AIDS (UNAIDS) untuk kawasan Asia tahun 20I2 diperkirakan, Indonesia menempati urutan ke-tiga (380.000) setelah urutan pertama di duduki oleh Tiongkok, sekitar 780.000 dan di Thailand sebanyak 490.000. Pengelola program Komisi Penanggulangan AIDS (KPA) Provinsi Bali, mengatakan bahwa hingga tahun 2018 terdapat lebih dari 200 ribu kasus HIVIAIDS di Indonesia (Tribun Bali, 2018). Denpasar merupakan kota yang paling tinggi angka kasus teridentifikasi HIVIAIDS dibandingkan dengan delapan kabupaten atau kota lainnya yang berada di Provinsi Bali.

Komisi Penanggulangan Aids Kota Denpasar (KPAD) adalah sebuah lembaga independen yang bertujuan meningkatkan upaya pencegahan dan penanggulangan AIDS yang lebih intensif, menyeluruh, terpadu dan terkoordinasi di kota Denpasar. KPAD memiliki beberapa kegiatan, diantaranya penyuluhan, dan konseling untuk penderita HIVIAIDS. KPAD bekerjasama dengan beberapa yayasan non-government yang berada di Denpasar-Bali untuk menanggulangi kasus HIVIAIDS.

Remaja yang mengetahui dirinya positif HIVIAIDS akan mengalami tekanan dalam hidupnya karena penyakit tersebut. HIV dan kesehatan mental sering digambarkan sebagai hubungan dua arah (bi-directional relationship), yang artinya dampak dari pengidap HIVIAIDS positif atau yang memiliki anggota keluarga yang terpapar HIVIAIDS dapat meningkatkan risiko penyakit mental, seperti depresi dan kecemasan (Briere \& Jordan, 2004; Cluver, Gardner, \& Operario, 2007; Cluver, Orkin, Gardner, \& Boyes, dalam Betancourt et al., 20I3). Cukup banyak kasus yang menunjukkan bahwa ketika remaja didiagnosis HIV, mereka menjadi depresi dan cenderung menarik diri dari lingkungan karena takut atas penolakan dan diskriminasi dari masyarakat sekitar.

Kenyataan di atas tercermin dari wawancara yang dilakukan oleh peneliti terhadap tujuh remaja dengan HIVIAIDS di Denpasar-Bali, yaitu lima diantaranya mengalami kecemasan dan depresi akibat ketakutan akan penolakan masyarakat dan memikirkan kematian akibat penyakit itu. Mereka mendapatkan penolakan dari teman-teman yaitu tidak ada yang mau bergaul dengannya, dan juga salah satu dari kelima remaja tersebut mengatakan mendapatkan penolakan dari keluarga besarnya karena statusnya saat ini. Penolakan dari masyarakat, membuat remaja menarik diri dari lingkungan. Reaksi dari masyarakat tersebut menjadi tekanan bagi para remaja. Hal tersebut mencerimkan kompetensi sosial yang kurang baik, dilihat dari kemampuan untuk membangun relasi dengan orang lain dan kemampuan untuk bertingkah laku sehingga mendapatkan respon positif dari orang lain terbilang kurang. Dua remaja lainnya tidak merasakan penolakan yang dilakukan oleh masyarakat lingkungan sekitar, tetapi memiliki keadaan emosional cukup tinggi. Mereka banyak mengeluh atau menyalahkan orang lain ketika terjadi konflik. Hal ini mencerminkan kompetensi sosial yang cukup baik, namun memiliki kemampuan memecahkan masalah yang kurang, dimana mereka masih terpaku pada permasalahan dan tidak bisa mencari solusi penyelesaian masalah.

Sebagian besar remaja memiliki pandangan bahwa mereka tidak dapat melanjutkan pendidikan dan cita-cita dikarenakan tidak memiliki keyakinan dan harapan untuk dapat melanjutkan cita-cita mereka. Mereka menjadi pesismis tidak dapat memiliki masa depan yang lebih baik. Hal ini mencerminkan bahwa sebagian besar remaja memiliki sense of purpose yang kurang baik yang dapat dilihat dari optimisme dan harapan mereka yang kurang.

Dari hasil survey awal yang telah dilakukan, dapat disimpulkan bahwa remaja dengan HIV/AIDS di DenpasarBali kurang memiliki resiliency yang tergambar dari kurangnya kemampuan sosial, kemampuan untuk menyelesaikan masalah dan sense of purpose. Remaja dengan HIVIAIDS di Denpasar-Bali perlu memiliki kemampuan untuk bisa menyesuaikan diri di tengah situasi yang menekan. Keberhasilnya remaja dengan HIVIAIDS beradaptasi dengan kondisi tersebut, akan menjadikan mereka memiliki semangat hidup lebih tinggi, mampu memaknai kehidupannya lebih baik, dan mampu membenahi kembali kehidupannya agar dapat mencapai tujuan yang diinginkan. Kemampuan untuk beradaptasi di tengah situasi yang sulit disebut dengan resiliency. Benard (2004), mendefinisikan resiliency sebagai kemampuan individu untuk beradaptasi dan berfungsi dengan baik di tengah keadaan yang menekan dan banyak halangan atau rintangan.

Menurut Benard (2004) yang dibutuhkan agar resiliency dapat berkembang dengan baik dan dapat memunculkan hasil yang baik adalah lingkungan yang dapat memenuhi kebutuhan dasar dan kebutuhan psikologis yang berupa kebutuhan afeksi, kebutuhan akan rasa memiliki, rasa aman, kemandirian, sense of competence, dan lain-lain. Keluarga memiliki peranan yang cukup besar dalam memenuhi kebutuhan dasar dan kebutuhan psikologis individu. Kehangatan dari pengasuhan orang tua merupakan faktor pendukung dari 
mental yang sehat, kemampuan akademis, dan sebagian besar dari fungsi-fungsi psikologis. Menurut Benard (2004) dalam kondisi yang ekstrim, faktor protektif yang paling dramatis pada individu adalah pengaruh dari orang tua. Penelitian yang dilakukan oleh Masten dan rekannya (dalam Benard (2004) menemukan bahwa kualitas dari pengasuhan orang tua adalah faktor protektif yang utama dalam menunjang perkembangan yang sehat dalam menghadapi kesulitan. Dalam hal faktor protektif selain struktur keluarga, parenting style juga ditemukan menjadi penentu utama dari fungsi keluarga yang efektif dan kesejahteraan bagi individu (McFarlane et al., dalam Benard, 2004).

Orang tua memiliki parenting style tersendiri dalam membimbing dan mengasuh anaknya. Secara umum parenting style dilakukan oleh Ayah dan Ibu, namun terdapat perbedaan pengasuhan anak yang dilakukan oleh Ayah dan Ibu. Menurut Psikolog Ajeng Raviando (dalam tabloid Bintang, 2016) perbedaan parenting style antara Ayah dan lbu disebabkan oleh parenting style yang mereka alami ketika masih kecil. Baumrind (I97I) mendefinisikan parenting style sebagai sikap dan perilaku orang tua yang berdampak pada perilaku anak. Terdapat tiga macam parenting style yaitu, authoritative, authoritarian, dan permissive. Ketiga parenting style tersebut ada didalam diri Ayah dan Ibu. Penelitian ini akan mengukur parenting style Ayah dan lbu.

Penelitian yang dilakukan oleh Permata \& Listiyandini (2015) mengenai peranan parenting style dalam memprediksi resiliency mahasiswa tahun pertama yang merantau di Jakarta menemukan bahwa, semua jenis parenting style kecuali permissive parenting style Ayah memiliki peranan terhadap resiliency. Parenting style yang memiliki peranan yang paling besar terhadap resiliency adalah authoritative parenting style baik Ayah maupun lbu. Penelitian lain yang dilakukan oleh Kritzas \& Grobler (2005) mengenai hubungan antara parenting style yang dirasakan dan resiliency selama masa remaja, menunjukkan bahwa perilaku pengasuhan yang positif baik dari Ayah maupun lbu dianggap sebagai faktor eksternal yang terbukti memiliki korelasi yang positif dengan resiliency.

Selain faktor protektif yang berasal dari lingkungan, faktor protektif juga bisa berasal dari dalam diri individu. Resiliency sering dikaitkan dengan coping dalam sejumlah konteks yang berbeda. Berkaitan dengan coping stres, penelitian yang dilakukan oleh Darmawanti (2012) mengenai hubungan antara tingkat religiusitas dengan kemampuan dalam mengatasi stres menemukan bahwa, terdapat korelasi yang signifikan antara religiusitas dengan coping stres yang dilakukan dengan mengendalikan tingkat stres. Agama memiliki peranan penting dalam mengelola stres, memberikan individu pengarahan atau bimbingan, dukungan, dan harapan (Pargament, dalam Utami, 20I2).

Salah satu bidang penelitian yang lebih menarik dalam beberapa tahun terakhir, berfokus pada hubungan antara religiusitas dan kesehatan fisik. Menurut George et al., (dalam Compton, 2005) individu yang lebih religius cenderung memiliki penyakit yang lebih sedikit, memiliki hidup yang lebih lama, cepat pulih dari penyakit atau operasi, dan memiliki toleransi yang lebih besar untuk rasa penyakit. Para peneliti telah menghipotesiskan bahwa agama mungkin mempengaruhi kesehatan fisik karena terdapat beberapa faktor tentang agama, salah satunya adalah agama menyediakan strategi coping yang unik (Pargament, Smith, Koenig and Perez; Emmons, dalam Compton, 2005). Beberapa penelitian telah dilakukan untuk melihat strategi coping mana yang paling efektif terhadap resiliency dan hasilnya menemukan bahwa strategi religious coping memiliki kontribusi yang cukup besar terhadap resiliency (Steinhardt \& Dolbier, 2008., Pratiwi, 2016).

Pargament (2007) mendefinisikan religious coping sebagai cara memahami dan menangani peristiwa kehidupan yang negatif yang berkaitan dengan kesakralan. Terdapat dua pola dalam religious coping, yaitu: positive religious coping dan negative religious coping. Penelitian yang dilakukan oleh Sari (2016) mengenai peran religious coping dan dukungan sosial terhadap resiliency pada janda usia madya pasca kematian pasangan hidup, menemukan bahwa religious coping dan dukungan sosial dapat memprediksi resiliency secara bersama-sama. Berbeda dengan penelitian yang dilakukan oleh Bell, dkk (2015) mengenai peran religious coping terhadap resiliency pada individu dengan dissociative identity disorder, menemukan bahwa religious coping memiliki korelasi yang tidak signifikan terhadap resiliency.

Berdasarkan uraian diatas, maka tujuan dari penelitian ini adalah untuk mengetahui peranan parenting style baik Ayah maupun Ibu dan religious coping terhadap resiliency pada remaja dengan HIVIAIDS di Denpasar-Bali. Manfaat penelitian ini adalah untuk dapat menambah keilmuan bagi kajian psikologi perkembangan dan psikologi keluarga, serta membantu remaja dengan HIVIAIDS, orang tua, dan masyarakat dalam membantu remaja meningkatkan resiliency. 


\section{Metode}

Responden dalam penelitian ini adalah remaja dengan HIVIAIDS di Denpasar-Bali yang berjumlah 103. Responden penelitian didapatkan di dua yayasan dibawah KPAD. Responden dalam penelitian ini berusia II sampai 22 tahun yang didominasi oleh remaja berusia 22 tahun. Kemudian sebagian besar responden merupakan pegawai swasta (62 remaja) selain itu, sebanyak 21 remaja masih duduk dibangku sekolah, 12 remaja tidak melanjutkan pendidikan, dan 8 remaja melanjutkan pendidikan di jenjang perguruan tinggi.

Penelitian ini menggunakan alat ukur resiliency, parenting style, dan religious coping. Alat ukur resiliency yang digunakan dalam penelitian ini adalah alat ukur yang dikonstruk oleh Edwina (2012). Kuesioner ini terdiri dari $5 \mathrm{I}$ item. Alat ukur resiliency memiliki hasil uji validitas antara 0,755-0,868, dan reliabilitas 0,859.

Alat ukur parenting style dibagi menjadi dua, yaitu parenting style Ayah dan parenting style Ibu. Alat ukur parenting style dalam penelitian ini adalah terjemahan peneliti dari Parental Authority Questionnaire (PAQ) yang dibuat oleh Buri (199I). PAQ memiliki tiga subskala yaitu: permissive, authoritarian, dan authoritative. Alat ukur parenting style Ayah dan lbu masing-masing terdiri dari 30 item. Alat ukur parenting style Ayah memiliki hasil uji validitas untuk parenting style Ayah authoritative berkisar antara 0,426-0,72I; parenting style ayah permissive berkisar antara 0,333-0,469; parenting style ibu authoritative berkisar antara 0,322-0,693; parenting style ibu authoritarian berkisar antara 0,379-0,609; dan parenting style ibu permissive berkisar antara 0,338-0,495. Hasil uji reliabilitas parenting style Ayah authoritative 0,646, parenting style Ayah authoritarian 0,839, parenting style Ayah permissive 0,589, parenting style lbu authoritative 0,763, parenting style lbu authoritarian 0,780, dan parenting style lbu permissive 0,629.

Alat ukur religious coping yang digunakan dalam penelitian ini adalah hasil terjemahan peneliti dari The Brief RCOPE yang dibuat oleh Pargament, Feuille dan Burdzy (20II). The Brief RCOPE terdiri dari I4 item yang dibagi menjadi dua subskala dan masing-masing terdiri dari 7 item yang mengidentifikasikan kelompok metode positive religious coping dan negative religious coping. Alat ukur religious coping memiliki hasil uji validitas berkisar antara 0,426-0,753, dan reliabilitas 0,842. Teknik analisis data dalam penelitian ini menggunakan multiple regression dan linear regression.

\section{Hasil}

Subjek dalam penelitian ini berjumlah 103 remaja dengan HIVIAIDS di Denpasar-Bali yang dideskripsikan berdasarkan usia, jenis kelamin, pekerjaan dan status pernikahan.

Tabel I.

Gambaran Subjek

\begin{tabular}{lll}
\hline & Jumlah Subjek & Persentase \\
\hline Usia & 1 & $0,9 \%$ \\
II tahun & 7 & $6,7 \%$ \\
I7 tahun & 13 & $12,6 \%$ \\
I8 tahun & 18 & $17,4 \%$ \\
I9 tahun & 14 & $13,5 \%$ \\
20 tahun & 16 & $15,5 \%$ \\
21 tahun & 34 & $33 \%$ \\
22 tahun & & \\
\hline Jenis Kelamin & 88 & $85,4 \%$ \\
Laki-laki & 15 & $14,5 \%$ \\
Perempuan & & \\
\hline Pekerjaan & 21 & $20,3 \%$ \\
Siswa & 8 & $7,7 \%$ \\
Mahasiswa & 12 & $11,6 \%$ \\
Tidak Sekolah & 62 & $60,1 \%$ \\
Swasta & 7 & $6,7 \%$ \\
\hline Status Pernikahan & 96 & $93,2 \%$ \\
Menikah & & \\
Belum Menikah & &
\end{tabular}


Hasil uji hipotesis penelitian secara bersama-sama menunjukkan bahwa variabel parenting style Ayah dan religious coping bersama-sama berperan secara signifikan terhadap resiliency $\left(\rho<.05, R^{2}=0,384\right)$. Selanjutnya, hasil uji hipotesis penelitian secara bersama-sama juga menunjukkan bahwa variabel parenting style lbu dan religious coping bersama-sama berperan secara signifikan terhadap resiliency $\left(\rho<.05, R^{2}=0,365\right)$.

Tabel I.

Hasil Uji Hipotesis Penelitian Secara Bersama-sama Parenting Style Ayah dan Religious Coping Serta Secara Bersama-Sama Parenting Style Ibu dan Religious Coping

\begin{tabular}{lllll}
\hline & R & R Square & F & Sig. \\
\hline Parenting Style Ayah dan Religious Coping & .620 & .384 & 12.116 & .000 \\
Parenting Style Ibu dan Religious Coping & .604 & .365 & 11.167 & .000 \\
\hline
\end{tabular}

Dependent variabel: Resiliency

Hasil uji hipotesis penelitian secara parsial menunjukkan bahwa tiga variabel bebas tidak berperan signifikan terhadap variabel terikat $(\rho>.05)$. Variabel-variabel bebas yang dimaksud adalah parenting style Ayah authoritarian, parenting style Ayah permissive dan positive religious coping tidak berperan signifikan terhadap resiliency. Selain itu, pada tabel 2 juga menunjukkan bahwa variabel bebas lainnya memiliki peran positif dan negatif yang signifikan terhadap variabel terikat $(\rho<.05)$. Variabel bebas tersebut adalah parenting style Ayah authoritative berperan positif dan signifikan terhadap resiliency dan negative religious coping memiliki peran negatif dan signifikan terhadap resiliency.

Tabel 2.

Hasil Uji Hipotesis Penelitian Secara Parsial Parenting Style Ayah dan Religious Coping

\begin{tabular}{llll}
\hline Variabel & Beta & t & Sig. \\
\hline Parenting style Ayah Authoritative & .449 & 5.239 & .000 \\
Parenting style Ayah Authoritarian & -.154 & -1.732 & .087 \\
Parenting style Ayah Permissive & -.104 & -1.140 & .257 \\
Positive Religious Coping & .117 & 1.400 & .165 \\
Negative Religious Coping & -.213 & -2.543 & .013 \\
\hline
\end{tabular}

Dependent variabel: Resiliency

Hasil uji hipotesis penelitian secara parsial menunjukkan bahwa keempat variabel bebas memiliki peran yang signifikan terhadap variabel terikat $(\rho<.05)$. Variabel-variabel bebas yang dimaksud adalah parenting style lbu authoritative memiliki peran positif dan signifikan terhadap resiliency sedangkan parenting style lbu authoritarian memiliki peran negatif dan signifikan terhadap resiliency, positive religious coping memiliki peran positif dan signifikan terhadap resiliency, dan negative religious coping memiliki peran negatif dan signifikan terhadap resiliency. Selain itu, pada tabel 3 juga menunjukkan bahwa variabel bebas lainnya tidak berperan signifikan terhadap variabel terikat $(\rho>.05)$. Variabel bebas tersebut adalah parenting style lbu permissive tidak berperan signifikan terhadap resiliency.

Tabel 3.

Hasil Uji Hipotesis Penelitian Secara Parsial Parenting Style Ibu dan Religious Coping

\begin{tabular}{llll}
\hline Variabel & Beta & t & Sig. \\
\hline Parenting style Ibu Authoritative & .320 & 3.876 & .000 \\
Parenting style Ibu Authoritarian & -.202 & -2.116 & .037 \\
Parenting style lbu Permissive & -.148 & -1.692 & .094 \\
Positive Religious Coping & .194 & 2.333 & .022 \\
Negative Religious Coping & -.199 & -2.204 & .030 \\
\hline
\end{tabular}

Dependent variabel: Resiliency

\section{Pembahasan}

Berdasarkan hasil pengujian secara bersama-sama, tabel I memaparkan hasil bahwa parenting style Ayah dan religious coping secara bersama-sama berperan secara signifikan terhadap resiliency $\left(\rho<.05, R^{2}=0,384\right)$ yang artinya parenting style Ayah baik authoritative, authoritarian, permissive, dan religious coping baik positive religious coping, dan negative religious coping secara bersama-sama berperan secara signifikan terhadap resiliency pada remaja dengan HIVIAIDS di Denpasar-Bali. Tabel I dapat dilihat bahwa parenting style Ayah dan religious 
coping memiliki peranan terhadap resiliency sebesar 0,384 dimana secara umum, faktor eksternal berupa parenting style dan faktor internal berupa religious coping, keduanya memberikan peranan yang signifikan terhadap resiliency.

Peneliti juga melakukan pengujian secara parsial untuk setiap parenting style Ayah dan religious coping terhadap resiliency. Tabel 2 didapatkan hasil bahwa, parenting style Ayah authoritative memiliki peran positif dan signifikan terhadap resiliency $(\rho<.05)$. Hal ini sejalan dengan penelitian yang dilakukan oleh Permata dan Listiyandini (2015) bahwa parenting style Ayah authoritative memiliki peranan terhadap resiliency. Remaja dengan HIVIAIDS yang menghayati Ayah yang authoritative, terbiasa dengan perlakuan Ayah yang membiasakan mereka untuk memberikan pendapat dan berdiskusi secara terbuka untuk menentukan aktivitas yang positif bagi remaja. Jika dihadapkan dengan hal-hal yang sulit sebagai remaja dengan HIVIAIDS, mereka akan melihat bahwa setiap permasalahan terdapat peluang-peluang untuk menyelesaikannya.

Selanjutnya, tabel 2 menunjukkan bahwa parenting style Ayah authoritarian tidak berperan signifikan terhadap resiliency $(\rho>.05)$. Hal tersebut dapat terjadi karena resiliency pada remaja dengan HIVIAIDS di DenpasarBali dapat dipengaruhi oleh faktor lain yakni, sekolah dan komunitas. Subjek dalam penelitian ini merupakan remaja yang sebagian masih duduk dibangku sekolah dan masuk dalam tahap perkembangan remaja akhir. Orientasi mereka terhadap teman sebaya lebih besar dibandingkan orientasi terhadap orang tua (Santrock, 2017). Menurut Benard (2004) salah satu yang paling penting dan konsisten ditemukan dalam penelitian mengenai resiliency adalah kekuatan dari sekolah dimana sekolah dapat memberikan dukungan pengasuhan. Benard (2004) mengatakan bahwa sekolah dapat melibatkan motivasi intrinsik setiap siswa. Hal tersebut dapat terjadi dengan memenuhi kebutuhan dasar psikologis untuk merasakan perasaan memiliki dan perasaan aman, mendapatkan kompetensi dan merasakan bahwa apa yang mereka pelajari memiliki makna.

Selain itu, dalam penelitian ini didapat pula hasil bahwa parenting style Ayah permissive tidak berperan signifikan terhadap resiliency $(\rho>.05)$. Hal tersebut dapat terjadi karena resiliency pada remaja dengan HIVIAIDS di Denpasar-Bali dapat dipengaruhi oleh faktor lain diluar pengasuhan yang lakukan oleh orang tua yakni, sekolah dan komunitas. Selain sekolah, komunitas juga dapat menjadi faktor yang mempengaruhi resiliency pada remaja. Penelitian yang dilakukan oleh Blythe \& Leffert (dalam Benard, 2004) menemukan bahwa jika keluarga yang peduli dan mendukung membuat perbedaan besar dalam kehidupan remaja, kepedulian dan dukungan dalam komunitas menjadi pelindung utama bagi remaja. Komunitas tidak hanya dapat membantu remaja secara akademik melainkan juga dapat membantu remaja memiliki keterampilan hidup.

Komunitas berpeluang menjadi salah satu faktor yang dapat mempengaruhi resiliency pada remaja karena sebagian besar subjek dalam penelitian ini merupakan remaja yang sudah memasuki dunia kerja dan memiliki komunitas yang dapat memberikan dukungan terkait dengan status yang mereka sandang saat ini. Menurut pekerja lapangan di salah satu yayasan yang ada di Denpasar, remaja tidak hanya memiliki satu komunitas yang ada di yayasan tetapi mereka juga memiliki komunitas lain diluar yayasan seperti, komunitas para gay, lesbian atau komunitas lainnya. Ketika bertemu, mereka tidak hanya saling menguatkan tetapi juga melakukan kegiatan lain seperti misalnya mendengarkan penyuluhan yang dilakukan oleh yayasan atau berpergian ke suatu tempat bersama. Melalui dukungan-dukungan yang mereka dapat dari komunitas, hal tersebut dapat memberikan potensi untuk meningkatkan resiliency pada remaja dalam menghadapi kondisinya saat ini.

Tabel 2 menunjukkan bahwa parenting style Ayah dan positive religious coping tidak berperan signifikan terhadap resiliency pada remaja $(\rho>05)$. Hal ini sejalan dengan penelitian yang dilakukan oleh Bell, dkk (20I5) yang menemukan bahwa positive religious coping tidak berperan signifikan terhadap resiliency. Bell, dkk (20I5) menjelaskan bahwa religious coping memiliki peluang untuk meningkatkan kesejahteraan psikologis pada individu yang memiliki kepribadian ganda. Secara teoretik dikatakan bahwa semakin remaja dengan HIVIAIDS menggunakan positive religious coping maka resiliencynya semakin meningkat. Hal tersebut dapat terjadi karena positive religious coping berhubungan dengan kesehatan dan juga kesejahteraan. Penelitian yang dilakukan oleh George, Koenig \& McCullough (dalam Compton, 2005) menemukan bahwa individu yang lebih religius cenderung memiliki lebih sedikit penyakit, hidup lebih lama, pulih lebih cepat dari penyakit atau operasi, dan memiliki toleransi yang lebih besar terhadap rasa sakit. Dapat dilihat bahwa positive religious coping menumbuhkan rasa optimis atau harapan yang dipupuk oleh keyakinan pada agama, dimana hal tersebut dapat membantu meningkatkan resiliency.

Menurut Pargament, Smith, Koenig \& Perez (dalam Compton, 2005) religious coping digunakan seseorang untuk menghadapi kesulitan dalam hidup misalnya, religious coping dapat membantu memberikan harapan. Positive religious coping tercermin dalam item seperti "mencari bantuan dari Tuhan dalam meredakan amarahku", dan "mencoba untuk melihat bagaimana Tuhan menguatkanku dalam situasi ini”, adalah contoh dari remaja yang menggunakan positive religious coping untuk memperkuat kesejahteraan mental saat 
menghadapi kenyataan hidup dengan HIVIAIDS. Negative religious coping tercermin dalam item seperti "mempertanyakan cinta Tuhan untuk saya", dan "bertanya-tanya apa yang saya lakukan sehingga Tuhan menghukum saya", dapat membahayakan kesehatan mental remaja. Jadi, ketika remaja dengan HIVIAIDS menggunakan religious coping baik itu positive religious coping maupun negative religious coping dapat memberikan kontribusi terhadap kesehatan mental atau dapat menolong mereka saat merasa putus asa ketika didiagnosis HIVIAIDS.

Selanjutnya, didapat pula hasil bahwa parenting style Ayah dan negative religious coping memiliki peran negatif dan signifikan terhadap resiliency $(\rho<.05)$. Hal ini sesuai dengan penelitian yang dilakukan oleh Mclntire \& Duncan (2013) yang mengatakan bahwa individu yang menggunakan negative religious coping memiliki tingkat resiliency yang rendah. Ketika remaja menggunakan negative religious coping mereka akan memiliki pandangan bahwa dunia adalah tempat yang rawan. Hal tersebut dapat membuat remaja mempertanyakan makna kehidupan dalam memperjuangkan agama dimana, mereka akan merasa bahwa permasalahan yang saat ini terjadi adalah karena Tuhan telah meninggalkan mereka.

Selain parenting style Ayah, penelitian ini juga meneliti tentang parenting style lbu. Peneliti melakukan pengujian secara bersama-sama antara parenting style Ibu dan religious coping terhadap resiliency. Berdasarkan tabel I, didapatkan hasil bahwa parenting style lbu dan religious coping secara bersama-sama berperan secara signifikan terhadap resiliency $\left(\rho<.05, R^{2}=0,365\right)$, yang artinya parenting style lbu baik authoritative, authoritarian, permissive, dan religious coping baik positive religious coping, dan negative religious coping secara bersama-sama berperan secara signifikan terhadap resiliency pada remaja dengan HIVIAIDS di Denpasar-Bali. Tabel 3 dapat dilihat bahwa parenting style lbu dan religious coping memiliki peranan terhadap resiliency sebesar 0,365 dimana secara umum, faktor eksternal berupa parenting style dan faktor internal berupa religious coping, memberikan peranan yang signifikan terhadap resiliency.

Selanjutnya, Peneliti melakukan pengujian secara parsial untuk setiap parenting style lbu dan religious coping terhadap resiliency (tabel 3) yang menunjukkan bahwa parenting style lbu authoritative memiliki peran positif dan signifikan terhadap resiliency yang artinya semakin lbu menerapkan authoritative parenting style maka hal tersebut dapat membuat resiliency remaja semakin meningkat. Hal ini sejalan dengan penelitian yang dilakukan oleh Permata dan Listiyandini (2015) dimana penelitian tersebut menemukan hasil bahwa parenting style yang sangat memiliki peranan terhadap resiliency adalah parenting style lbu authoritative. Remaja dengan HIVIAIDS yang menghayati lbu yang authoritative akan menjadi remaja yang mandiri karena terbiasa dengan kebebasan yang lbu berikan untuk mengembangkan kemandiriannya. Dengan adanya kemandirian, hal tersebut akan memudahkan mereka untuk beradaptasi pada lingkungan sehingga mereka akan lebih mudah mengembangkan resiliencynya.

Selanjutnya adalah parenting style lbu authoritarian yang memiliki peran negatif dan signifikan terhadap resiliency $(\rho<.05)$. Hasil ini sejalan dengan penelitian yang dilakukan oleh Ritter (dalam Zakeri, Jowkar, dan Razmjoee, 20l0) dimana dalam penelitiannya, ditemukan hasil bahwa parenting style authoritarian berhubungan dengan resiliency yang rendah, yang artinya semakin lbu menerapkan authoritarian parenting style maka resiliency akan menurun. Remaja dengan HIVIAIDS yang menghayati lbu yang authoritarian menghayati bahwa lbu selalu menetapkan aturan untuk mereka, dimana hal itu akan membuat remaja menjadi tidak mandiri karena terbiasa dengan aturan dan keputusan yang ditetapkan oleh lbu. Hal tersebut akan membuat remaja mengalami kesulitan ketika mereka harus memecahkan permasalahan yang terjadi.

Terakhir adalah parenting style lbu permissive tidak berperan signifikan terhadap resiliency $(\rho>.05)$. Hal tersebut dapat terjadi karena resiliency pada remaja dengan HIVIAIDS di Denpasar-Bali dapat dipengaruhi oleh faktor lain yaitu, sekolah dan komunitas. Benard (2004) mengatakan bahwa tiga faktor protektif yang dapat mempengaruhi resiliency secara konsisten dapat ditemukan dalam keluarga, sekolah dan komunitas. Selain di sekolah dan di lingkungan kerja, mereka juga memiliki komunitas terkait dengan status yang mereka sandang yaitu, remaja dengan HIVIAIDS. Mereka tidak hanya mendapatkan dukungan dari keluarga, tetapi mereka juga mendapatkan dukungan dari teman sebaya dan komunitas mereka. Penelitian yang dilakukan oleh Battistich (200I); Watson \& Ecken (dalam Benard, 2004) melaporkan bahwa kepedulian yang didapatkan di sekolah dan komunitas dapat meningkatkan perkembangan yang positif pada remaja.

Peneliti juga mendapat hasil mengenai peran religious coping secara bersama-sama dengan parenting style lbu terhadap resiliency. Berdasarkan tabel 4.8, didapatkan hasil bahwa parenting style lbu dan positive religious coping memiliki peran positif dan signifikan terhadap resiliency $(\rho<.05)$. Hal ini sejalan dengan penelitian yang dilakukan oleh Mclntire \& Duncan (2013) yang mengatakan bahwa individu yang menggunakan positive religious coping memiliki tingkat resiliency yang tinggi. Positive religious coping dapat membantu remaja dengan HIVIAIDS ketika mereka merasa pesimis saat menghadapi kesulitan dalam kehidupan sehari-hari, dimana 
keyakinan dari adanya makna dalam kehidupan akan membantu remaja percaya bahwa mereka dapat melewati kesulitan dalam hidupnya.

Religious coping yang terakhir adalah parenting style lbu dan negative religious coping yang memiliki peranan negatif dan signifikan terhadap resiliency $(\rho<.05)$. Hasil penelitian ini sejalan dengan penelitian yang dilakukan oleh Mclntire \& Duncan (2013) dimana hasil penelitiannya mengatakan bahwa individu yang menggunakan negative religious coping memiliki tingkat resiliency yang rendah. Remaja yang menggunakan negative religious coping memiliki hubungan yang kurang aman dengan Tuhan, dimana hal tersebut membuat mereka merasa dihukum oleh Tuhan atas apa yang terjadi dalam hidupnya.

\section{Kesimpulan}

Berdasarkan hasil penelitian yang telah dilakukan, maka dapat disimpulkan hal-hal yaitu, parenting style yang berperan signifikan terhadap resiliency adalah parenting style authoritative, baik Ayah maupun lbu, dan parenting style authoritarian Ibu. Parenting style permissive, baik Ayah maupun Ibu dan parenting style authoritarian Ayah tidak berperan signifikan terhadap resiliency. Parenting style lbu dan negative religious coping serta positive religious coping berperan signifikan terhadap resiliency. Parenting style Ayah dan positive religious coping tidak berperan signifikan terhadap resiliency, parenting style Ayah dan negative religious coping berperan signifikan terhadap resiliency. Parenting style Ayah dan religious coping secara bersama-sama memiliki peran yang signifikan terhadap resiliency pada remaja dengan HIVIAIDS di Denpasar-Bali. Parenting style lbu dan religious coping secara bersama-sama memiliki peran yang signifikan terhadap resiliency pada remaja dengan HIVIAIDS di Denpasar-Bali.

Bagi peneliti selanjutnya diharapkan dapat meneliti mengenai resiliency dengan menguji peran dari faktor lain yaitu, sekolah atau komunitas. Selain itu, dapat juga meneliti mengenai resiliency dengan parenting style yang dimediasi oleh religious coping. Selanjutnya, dapat meneliti resiliency dengan menggunakan koping jenis lain.

Bagi orang tua baik Ayah maupun lbu diharapkan dapat berupaya mengarahkan aktivitas anak, seperti mendukung pengembangan diri anak dengan cara yang rasional dan berorientasi pada masalah. Selain itu, Ayah maupun lbu juga dapat mendorong timbal balik secara verbal, dan memberikan alasan mengapa aturan ditegakan dalam keluarga agar dapat membantu remaja dengan HIVIAIDS di Denpasar-Bali untuk beradaptasi dan berfungsi dengan baik ditengah keadaan yang menekan dan banyak halangan atau rintangan.

Bagi para remaja dengan HIVIAIDS di Denpasar-Bali, diharapkan mampu mengembangkan hubungan yang lebih kuat dengan Tuhan, mencari bantuan Tuhan untuk meredakan amarah, mampu mencoba untuk menjalankan rencana bersama dengan Tuhan, dan mencoba untuk melihat bagaimana Tuhan menguatkan ketika remaja dalam situasi yang sulit serta menghindari perasaan dihukum oleh Tuhan karena kurangnya ketaat dalam beribadah, bertanya-tanya apakah Tuhan meninggalkan remaja, dan mempertanyakan cinta Tuhan.

Bagi yayasan-yayasan yang terkait, KPAD, maupun dinas sosial diharapkan dapat melakukan penyuluhan baik kepada para remaja maupun orang tua tentang pentingnya menerapkan authoritative parenting style dan juga pentingnya mengembangkan positive religious coping agar para remaja dengan HIVIAIDS di Denpasar-Bali dapat beradaptasi dan berfungsi dengan baik ditengah keadaan yang menekan dan banyak halangan atau rintangan.

\section{REFERENSI}

Baumrind, D. (197I). Current patterns of parental authority. Developmental Psychology Monograph, 4.

Bell, H., Jacobson, L., Zeligman, M., Fox, J., \& Hundley, G. (2017). The Role of Religious Coping and Resilience in Individuals with Dissociative Identity Disorder. Counseling and Values, 60.

Benard, B. (2004). Resiliency what we have learned. San Francisco: WestEd.

Betancourt, T., Ohki, S., Charroe, A., \& Hansen, N. (20I3). Annual research review: Mental health and resilience in HIVIAIDS-affected children - A review of the literature and recommendations for future research. Journal of Child and Psychology, 54(4). 
Briere, J., \& Jordan, C.E. (2004). Violence against women: Outcome complexity and implications for assessment and treatment. Journal of Interpersonal Violence, 19, I252-I 276.

Buri, J.R. (199I). Parental authority questionnaire. Journal of Personality and Social Assessment, 57, I I0-I I 9.

Cluver, L., Gardner, F., \& Operario, D. (2007). Psychological distress amongst AIDS-orphaned children in urban South Africa. Journal of Child Psychology and Psychiatry, 48, 755- 763.

Cluver, L.D., Orkin, M., Gardner, F., \& Boyes, M.E. (20I2). Persisting mental health problems among AIDSorphaned children in South Africa. Journal of Child Psychology and Psychiatry, 53, 363-370.

Compton, W. (2005). An introduction to positive psychology. Wadsworth.

Darmawanti, I. (20I2). Hubungan antara Tingkat Religiusitas dengan Kemampuan dalam Mengatasi Stres (Coping Stress). Jurnal psikologi teori dan terapan.

Edwina, O. (2012). Pengaruh faktor kepribadian (trait), proteksi, dan risiko terhadap resilience pada remaja usia 15-I 8 Tahun di Kotamadya Bandung. Bandung: Universitas Padjajaran Bandung.

Kritzas, N., Grobler, A. (2005). The relationship between perceived parenting styles and resilience during adolescence. Journal of Child and Adolescence Mental Health, University of the Free State South Africa.

Komisi Penanggulangan AIDS Provinsi Bali. 20I4. Estimasi populasi kunci dan orang dengan HIVIAIDS (ODHA) tahun 2014 di Kabupaten/Kota dan Provinsi Bali. Bali: Komisi Penanggulangan AIDS Provinsi Bali.

Komisi Penanggulangan AIDS Provinsi Bali. 2018. Kumulatif kasus HIVIAIDS menurut perkiraan faktor resiko dan jenis kelamin dari tahun 1987-september 2018 di Provinsi Bali. Bali: Komisi Penanggulangan AIDS Provinsi Bali.

Mclntire, L., \& Duncan, R. (20I3). Associations among religious coping, daily hassles, and resilience. Archieve for the Psychology of Religion 35.

Santrock, J. (20I7). Life-span development sixteenth edition. New York: McGraw-Hill Companies.

Sari, W. (2016). Peran koping religius dan dukungan sosial terhadap resiliensi pada janda usia madya pasca kematian pasangan hidup. Universitas Gadjah Mada.

Steinhardt, M., Dolbier, C. (2008). Evaluation of a resilience intervention to enhance coping strategies and protective factors and decrease symptomatology. Journal of American College Health, 56.

Suputra, D. (2018, July). Pengidap HIVIAIDS terbanyak di Denpasar, 75 persen berusia I5-39 tahun. Tribun Bali. Diunduh dari: http://bali.tribunnews.com/2018/07/02/pengidap-hivaids-terbanyak-di-denpasar75-persen-berusia-I5-39-tahun?page=I

Pargament, K., \& Raiya, H. (2007). A decade of research on the psychology of religion and coping: Things We Assumed and Lessons We Learned. Psyke \& Logos.

Pargament, K., Feuille, M., \& Burdzy, D. (20II). The brief RCOPE: Current psychometric status of a short measure of religious coping. Journal Religions.

Permata, D., Listiyandini, R. (20I5). Peranan pola asuh orang tua dalam memprediksi resiliensi mahasiswa tahum pertama yang merantau di Jakarta: Prosiding Pesat Universitas Gunadarma.

Pratiwi, A., Hirmaningsih. (20I6). Hubungan coping dan resiliensi pada perempuan kepala rumah tangga miskin. Jurnal Psikologi, I2(2).

Utami, M. (2012). Religiusitas, Koping Religius, dan Kesejahteraan Subjektif. Jurnal Psikologi, 39(I).

Yuri. (2016, May). Ayah dan lbu beda cara dalam hal mengasuh anak, bagaimana jalan tengahnya?. Tabloid Bintang. Diunduh dari: https://www.aura.co.id/psikologi/read/38473/ayah-dan-ibu-beda-cara-dalamhal-mengasuh-anak-bagaimana-jalan-tengahnya 
Zakeri, H, Jowkar, B., \& Razmjoee, M. (2010). Parenting styles and resiliency. Procedia Social and Behavioral Science 5. 